NASA Technical Memorandum 102835

\title{
A Direct-Interface, Fusible Heat Sink for Astronaut Cooling
}

\section{Curtis Lomax and B. W. Webbon}

May 1990

\section{(NASA-TM-10203
FUSTALE HEAT
(NASA) 150}


5

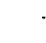

$=-$

. 
NASA Technical Memorandum 102835

\section{A Direct-Interface, Fusible Heat Sink for Astronaut Cooling}

Curtis Lomax and B. W. Webbon

Ames Research Center, Moffett Field, California

May 1990

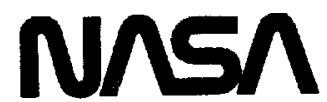

National Aeronautics and

Space Administration 
. 


\section{ABSTRACT}

Astronaut cooling during extravehicular activity is a critical design issue in developing a portable life support system that meets the requirements of a space station mission. Some of the requirements are that the cooling device be easily regenerable and nonventing during operation. In response to this, a direct-interface, fusible heat sink prototype with freezable quick-disconnects has been developed. A proof-of-concept prototype has been constructed and tested that consists of an elastic container filled with normal tap water and having two quickdisconnects embedded in a wall. These quickdisconnects are designed so that they may be frozen with the ice and yet still be joined to the cooling system, allowing an immediate flow path. The inherent difficulties in a direct-interface heat sink have been overcome, i.e., (1) establishing an initial flow path, (2) avoiding low-flow freeze-up, and (3) achieving adequate heat-transfer rates at the end of the melting process. The requirements, design, fabrication, and testing are discussed.

\section{INTAODUCTION}

During extravehicular activity (EVA) a crew member generates metabolic energy, while portable life support systems (PLSS) and equipment produce additional heat. Ninety percent of metabolic energy is in the form of waste heat (1)" that must be removed from the body during the EVA to allow crew comfort and performance. Once removed from the body, the heat may be either stored or rejected, or both. On orbit, heat rejection occurs only by radiation or mass transfer. Heat storage may be accomplished

\footnotetext{
"Numbers in parentheses designate reterences at end of paper.
}

by inducing a phase change in a substance or by causing an endothermic reaction to take place. Any self-contained system that attempts to control the thermal condition of an astronaut wearing a space suit will be limited by either capacity or rate of heat transfer. For example, a storage system will be limited by capacity, as will a mass transter system. A radiation system will be limited by heat-transfer rate.

Thermal regulation of astronauts during EVA has been studied in some detail. In the past, cooling of space-suited crew members has been accomplished by use of a sublimator or an umbilical coolant supply. These systems provide adequate capacity and rate and are compact and lightweight. Their disadvantages are the venting and subsequent loss of water during operation or awkward umbilicals to manage. Future PLSS will require thermal regulatory systems that are nonventing, regenerable, and selfcontained.

A nonventing, regenerable, and self-contained thermal regulatory proof-of-concept prototype has been developed. The prototype uses the solid-toliquid phase-change properties of water to store waste heat. The device is a direct-interface, fusible heat sink. This paper discusses the requirements, design, fabrication, and testing of $\Sigma$ 1/3-capacity, proof-of-concept prototype.

\section{REQUIREMENTS}

Future exploration missions will require an EVA system that can provide routine, possibly daily, operation that continues for months without support or resupply from surface-based resources or facilities. For these reasons, the thermal regulation system must be easily regenerable, nonventing, and extremely reliable. Some specific requirements are that the total capacity be $11680 \mathrm{Btu}(3420 \mathrm{~W}$-hr) for an 8-hr EVA and that the device be able to cool at 
$2000 \mathrm{Btu} / \mathrm{hr}$ (585.6 W) for $15 \mathrm{~min}$ any time during this 8-hr period (5). More specific requirements are detailed in Table 1. The current proof-of-concept prototype is a 1/3 model (4000-Btu) (1171 W-hr).

\section{DESIGN}

There have been numerous astronaut cooling devices that use fusible heat sinks $(2,3,4)$ However, none demonstrated a direct interface between the cooling liquid transport loop and the phase-change material; all of the previous designs have incorporated heat exchangers. This new design eliminates the use of a heat exchanger and allows directcontact, forced-convection heat transfer between the cooling fluid and the phase change material. The benefits of this are reduced hardware weight, thermal resistance, and system complexity. The critical points of this design are the initial coolant flow path and adequate heat-transfer rate during the end of the melting process, as well as the design of quickdisconnects that seal to preclude microgravity fluid management problems.

If the requirement for cooling is 11680 Btu (3420 W-hr) per EVA (5), and if ice cooled to $0^{\circ} \mathrm{F}$ $\left(-17.8^{\circ} \mathrm{C}\right)$ and melt water warmed to $40^{\circ} \mathrm{F}\left(4.4^{\circ} \mathrm{C}\right)$ is used as a phase change material, then approximately $70 \mathrm{lb}(31.7 \mathrm{~kg})$ of water must be included in the full-capacity device. This corresponds to $1.12 \mathrm{t}^{3}$ $\left(.032 \mathrm{~m}^{3}\right)$ for water or $1.25 \mathrm{tt}^{3}$. $\left(.035 \mathrm{~m}^{3}\right)$ for ice. Conservatively estimating $30 \mathrm{lb}(13.6 \mathrm{~kg})$ for hardware, this gives a total weight of $100 \mathrm{lb}(45.3 \mathrm{~kg})$ for this thermal regulatory system.

The design consists of an elastic bladder cast from a two-part polyurethane elastomer that contains the water and ice and that is penetrated by two female connectors. The bladder is filled with water until it is in slight tension. Upon freezing, the bladder is stretched slightly owing to the expansion of the ice. When the first water is pumped into the bladder, the flexible wall is separated from the ice, stretching the bladder even more. Figure 1 illustrates this process. As the ice melts, the bladder relaxes and when the pump stops, at the end of the EVA, the bladder is again under slight tension. The container may be disconnected and refrozen at this point and the process repeated.

The initial coolant flow path is created by use of specially designed, freezable quick-disconnects (patent applied for) that allow the heat sink to be connected into the cooling loop and provide for a flow path. There are two identical connectors, each with a male and female portion. The two female portions of the connectors are embedded in the elastic wall of the heat sink and frozen with it. Following regeneration of the ice container in a separate freezer, the male portions are inserted into the female halves and the flow is initiated. The water flows through the first male portion and into the empty cavity of the first female portion. Since the path is blocked by ice, the water then returns through an annular passage in the first male portion and travels through an external line to the second male portion. Upon exiting the second male portion, the water continues the circuit through the pump and liquid-cooled ventilation garment (LCVG) worn by the astronaut and returns to the first male portion. The warm water quickly melts the ice in the fermale haff of the connector. Once the ice around the female portions has melted, the external bypass line is closed and all flow passes between the ice and the elastic bladder from inlet to outlet. Figures 2-4 show the mechanical aspects of the connectors.

The metabolic heat load will vary during the entire EVA, as will the potential heat-sink transfer rate. The latter is due to the changing surface area of the lice that the warm water encounters during the melt. The sink heat-transfer rate is controlled by adjusting the mass flow rate though the heat sink by a diverter valve. During low metabolic heat load conditions, only a small percentage of the $240 \mathrm{lb} / \mathrm{hr}$ $(108.7 \mathrm{~kg} / \mathrm{hr})$ mass flow is diverted through the heat sink. During high metabolic heat load, a larger percentage is diverted. If, for example, a constant metabolic heat load is assumed throughout the melt, the mass flow rate through the heat sink must gradually increase as the melt progresses in order to maintain the heat-transfer rate. It is necessary that the device be designed such that adequate mixing occurs durIng the later stages of the melt in order to maintain proper heat-transfer rates and to fully utilize the phase change material.

\section{FABRICATION}

A test article was constructed to verify that the direct-interface, fusible heat sink concept was viable. The test article was arbitrarily chosen to be approximately $1 / 3$ capacity, that is, it contained $1 / 3$ the mass a system would need for a theoretical 8-hr EVA. Approximately $23 \mathrm{lb}(10.4 \mathrm{~kg})$ of water were used and the total heat capacity was 3841 Btu (1125 W-hr).

The construction of the experimental elastic bladder consists of two parts, a lid and a bucket that are held together by a metal clamp. The bucket and lids were made in two-part molds using a polyurethane elastomer. The clamp was machined from 
Aluminium 6061-T6 and anodized black. Details of the assembly are presented in Figure 5.

Modifications were made to the test article as tests progressed. Three different lids were made, each lid with a different characteristic that testing indicated could be a possible improvement. Of the three lids, one accepted Tygon tubing without connectors, one accepted connectors, and one accepted connectors and included a baffle inside the bucket. The baffle was fixed to the undersurface of the lid and extended down to within 0.25 in. of the bottom of the bucket.

The connectors were made from a combination of Teflon-impregnated Delrin, O-rings, and stainless steel springs. All design and manufacturing were done in-house at NASA Ames Research Center .

\section{TESTING}

The prototype was frozen in a common household freezer, a process that took approximately $36 \mathrm{hr}$ to complete. The prototype was suspended in a wood and fiberglass rack, allowing heat transfer only by free convection and radiation. Use of forced convection or conduction could increase the heat transfer rate from 10 to 100 times, thus decreasing the time to freeze significantly (6). (A future device will attempt to demonstrate reduced freeze time.) Upon extraction from the freezer, the unit was connected to the test apparatus and the pump was turned on. The test apparatus consisted of a variable-speed gear pump (Micropump model No. 120-306), a flow meter (Hedland Ram Flow sensor 645-002 and Signal conditioner 520-100), a regulator valve (Whitey SS-7RSB), T-type thermocouples, an HX-50 heat source made by Neslab Inc., Tygon tubing B-44-4X, and assorted Swagelog fittings. The thermocouple and flow data were collected via a data-acquisition peripheral (IDAC 3000 and Macontrol sottware) and subsequent calculations were performed on a Macintosh II using the spreadsheet Excel. This equipment was assembled such that, once the heat sink was plumbed in, one could control the flow and temperature into it. Figure 6 diagrams the test apparatus. The thermocouples monitored inlet and outlet temperature and the flow meter registered inlet flow.

Testing criteria consisted of two items. The primary criterion was that the device must be operable. That is, that one must be able to freeze the device, connect it into the coolant loop, and establish a flow path. The secondary criterion was that the heattransfer rate be adequate until all the ice was melted. The first criterion could be judged by observation and the second by measurement of three parame- ters: (1) flow rate through the heat sink, (2) inlet temperature, and (3) outlet temperature. These measurements can be used to calculate the heattransfer rate into the heat sink. The heat-transfer rate determinations were only approximations during these proof-of-concept tests because the prototype was not insulated.

The test procedure was as follows.

1. Freeze the container.

2. Tum on the Neslab heat source and set temperature.

3. Connect the container into the coolant loop.

4. Initiate coolant flow through the container, $240 \mathrm{lb} / \mathrm{hr}(109 \mathrm{~kg} / \mathrm{hr})$, while measuring the parameters described above, and leave the device undisturbed throughout the melt. Observation of the melt process is important to determine the time it takes to completely melt the ice. Realistically, the device would be disturbed during normal use, but an undisturbed device was thought to provide a worst-case condition, since any motion would increase the heattransfer rate. This procedure was followed for each of the configurations described below.

Four different configurations of the article were tested with numerous repetitions of each. The four configurations (Table 2) consisted of using the three lids at laminar inlet flow conditions for the first three tests and using the one lid that accommodated connectors at turbulent flow conditions for the fourth test. Each configuration was tested to determine the maximum heat-transfer rate possible for the given configuration.

\section{DISCUSSION}

The first test article (no connectors) was filled with tap water and cuoled to approximately $4^{\circ} \mathrm{F}$ $\left(-15.6^{\circ} \mathrm{C}\right)$. This article did not have connectors; it could accept 5/8-in. (15.9-mrn) Tygon tubing after freezing. Upon connection of the Tygon tubing, the flow was initiated. The water proce i fed to flow from inlet to outlet, forcing its way between. he ice and the elastic bladder. This was confirmation that the concept of forming the initial flow path in a directintertace fusible heat sink was possible and practical. Figure 7 shows the heat-transfer profile for this experiment. The heat-transfer rate dropped below $2000 \mathrm{Btu} / \mathrm{hr}$ ( $585.6 \mathrm{~W}$ ) betore all the ice was melted, presumably owing to channeling of the flow around the ice block. In subsequent tests, it was evident that the low heat-transfer rate was due to channeling because shaking of the device increased the heattransfer rate significantly. It should be noted that all these tests were conducted in a 1-g environment 
and that microgravity conditions could change the performance of these prototypes. A reduction in buoyant forces would be expected to preclude the formation of density gradients that inhibit mixing. Therefore, the devices performance in microgravity during melting is expected to be improved over the 1-g case. Therefore, design altematives that would increase the quality of mixing and, consequently, the heat-transfer rate were investigated. The alternatives sought were those that would provide mixing without added power, complexity, or reduction in reliability.

The second test article (connectors/no baffles) did incorporate quick-disconnects but no baffles and it too had successful flow initialization. The inlet velocity was low and the inlet flow was laminar. Figure 8 shows the heat-transfer profile for this test. The minimum heat-transfer rate, $2000 \mathrm{Btu} / \mathrm{hr}(585.6 \mathrm{~W})$ could not be maintained throughout the melt. Unlike the first configuration, the connectors directed the flow parallel to the lid. This flow direction increased channeling, resulting in a decrease in the heattransfer rate. It is important to note that the ice was held down by the connectors as they protruded downward from the top of the container. The ice metted from the top down and once there was a large enough cavity to allow laminar flow (see Fig. 9) between inlet and outlet, the heat-transfer rate dropped dramatically, as shown in Figure 8. The heat-transfer profile in Figure 8 shows an increase in the heat-transfer rate at the end of the melt; this is due to the ice breaking loose from the connectors and floating up to the surface where it was in the flow path of the warmer water.

The third test article (connector / baffles) also had successful flow initiation. The heat-transfer rate profile was similar to that of the second prototype. The bafile seemed to have little if any effect on the heat-transfer rate. Again, the rise in heat-transfer rate at the end of the melt, as seen in Figure 10, is due to the ice breaking away from the connectors and floating to the surface.

All of the above configurations were successful in terms of initial coolant flow path, but were inadequate in terms of heat-transfer rate profiles. It was apparent that insufficient mixing inside the ice container was the cause, and another approach was investigated. The quick-disconnects were adjusted to increase the velocity at the inlet and thus provide a jetting action that would increase turbulence. The fourth configuration is identical to the three previous configurations except for inlet velocity and lack of baffles.
The fourth configuration was identical to the second, but the inlet velocity was increased, while the mass flow rate was maintained. Examination of Figure 11 shows the heat-transfer rate profile to be changed substantially. The heat-transfer rate was maintained above the minimum of $2000 \mathrm{Btu} / \mathrm{hr}$ (585.6 W) until and after all the ice was melted. Again, the test conditions sought to transfer heat into the ice as quickly as possible, and the charts represent the highest rates attainable for each configuration. This configuration was successful in both test criteria.

\section{CONCLUSIONS}

A direct-interface fusible heat sink has been constructed and tested. It performed adequately when judged by two criteria: (1) a heat-transfer rate during any time of the melt greater than $2000 \mathrm{Btu} / \mathrm{hr}$ $(585.6 \mathrm{~W})$ and (2) provision of a flow path during start-up operations. A flight-quality heat sink would probably weigh less than $100 \mathrm{lb}(\mathbf{4 5 . 3} \mathrm{kg})$. The system is a viable method of thermal regulation and should be developed further for use during Space Station Freedom and exploration mission EVA. A full-scale working prototype that will be used in neutral buoyancy evaluations of space suits is planned.

\section{REFERENCES}

(1) J. L. Williams, B. W. Webbon, R. L. Copeland, Advanced Extravehicular Protective Study, Detailed Technical Notes. Unpublished.

(2) G. J. Roebelen, Jr., Fusible Heat Sink for EVA Thermal Control. Hamilton Standard. Tasks 1-5, May 1978.

(3) B. W. Webbon, Concept Evaluation Test of a Fusible Evaporative Astronaut Heat Sink, VMSC Report 00.1452, Voight Missiles and Space Co. July 1971.

(4) G. J. Roebelen, Jr. Ice Pack Heat Sink Subsystem - Phase I, Hamilton Standard Aircraft Corp, Windsor Locks, Connecticut June 1973. NASA CR-114624, SVHSER 6223. 
(5) G. J. Roebelen, K. J. Dresser, E. W. Hodgson, and Chin Lin, RNT Control Subsystem for Extravehicular Activity, Hamilton Standard Div. of United Technologies Corp., Windsor Locks, Connecticut,
SAE paper, Thirteenth Intersociety Conference on Environmental Systems, July 1983.

6) Holman, J. P., Heat-transfer, 6th ed. McGraw-Hill Book Co. New York. 1986.

Table 1. Design and Performance Requirements

\begin{tabular}{|c|c|}
\hline $\begin{array}{l}\text { EVA duration } \\
\text { EVA environment }\end{array}$ & $\begin{array}{l}\text { 8hr (5) } \\
\text { LEO (any orientation) }\end{array}$ \\
\hline $\begin{array}{l}\text { Environment load } \\
\text { Metabolic heat load } \\
\text { Minimum } \\
\text { Average } \\
\text { Maximum } \\
\text { PLSS heat load } \\
\text { Net Heat Load }\end{array}$ & $\begin{array}{l}\text { O Btu/hr ( O W) (5) } \\
400 \text { Btu/hr }(117 \mathrm{~W}) \\
1000 \mathrm{Btw} / \mathrm{hr}(293 \mathrm{~W}) \\
2000 \mathrm{Btw} / \mathrm{hr}(586 \mathrm{~W})(5) \\
\text { Average, } 635 \mathrm{Btu} / \mathrm{hr}(186 \mathrm{~W})\end{array}$ \\
\hline $\begin{array}{l}\text { Minimum } \\
\text { 8-hr average } \\
\text { 15-min max } \\
\text { Total heat capacity } \\
\end{array}$ & $\begin{array}{l}635 \mathrm{Btu} / \mathrm{hr}(186 \mathrm{~W}) \\
1500 \mathrm{Btw} / \mathrm{hr}(439 \mathrm{~W}) \\
2000 \mathrm{Btu} / \mathrm{hr} 586 \mathrm{~W})(5) \\
11680 \mathrm{Btu}(3420 \mathrm{~W})(5) \\
\end{array}$ \\
\hline $\begin{array}{l}\text { Cooling garment temperatures } \\
\text { Minimum } \\
\text { Maximum } \\
\text { Heat-sink outlet temperature }\end{array}$ & $\begin{array}{l}60^{\circ} \mathrm{F}\left(15.5^{\circ} \mathrm{C}\right)(5) \\
85^{\circ} \mathrm{F}\left(29.4^{\circ} \mathrm{C}\right) \\
<40^{\circ} \mathrm{F}\left(4.4^{\circ} \mathrm{C}\right) \text { (humidity control) }\end{array}$ \\
\hline $\begin{array}{l}\text { Regeneration time } \\
\text { EVA frequency } \\
\text { Mission duration } \\
\text { Operational lifetime }\end{array}$ & $\begin{array}{l}\text { Less than } 16 \mathrm{hr} \\
8 \mathrm{hr} / \text { day, } 6 \text { day } / \mathrm{Wk} \\
6 \mathrm{mo} \\
>1228 \mathrm{hr} \\
\end{array}$ \\
\hline
\end{tabular}

Table 2. Prototype and Test Conditions

\begin{tabular}{lccc}
\hline Config. & Connector & $\begin{array}{c}\text { Inlet } \\
\text { velocity }\end{array}$ & Baffles \\
\hline First & No & Low & No \\
Second & Yes & Low & No \\
Third & Yes & Low & Yes \\
Fourth & Yes & High & No \\
\hline
\end{tabular}



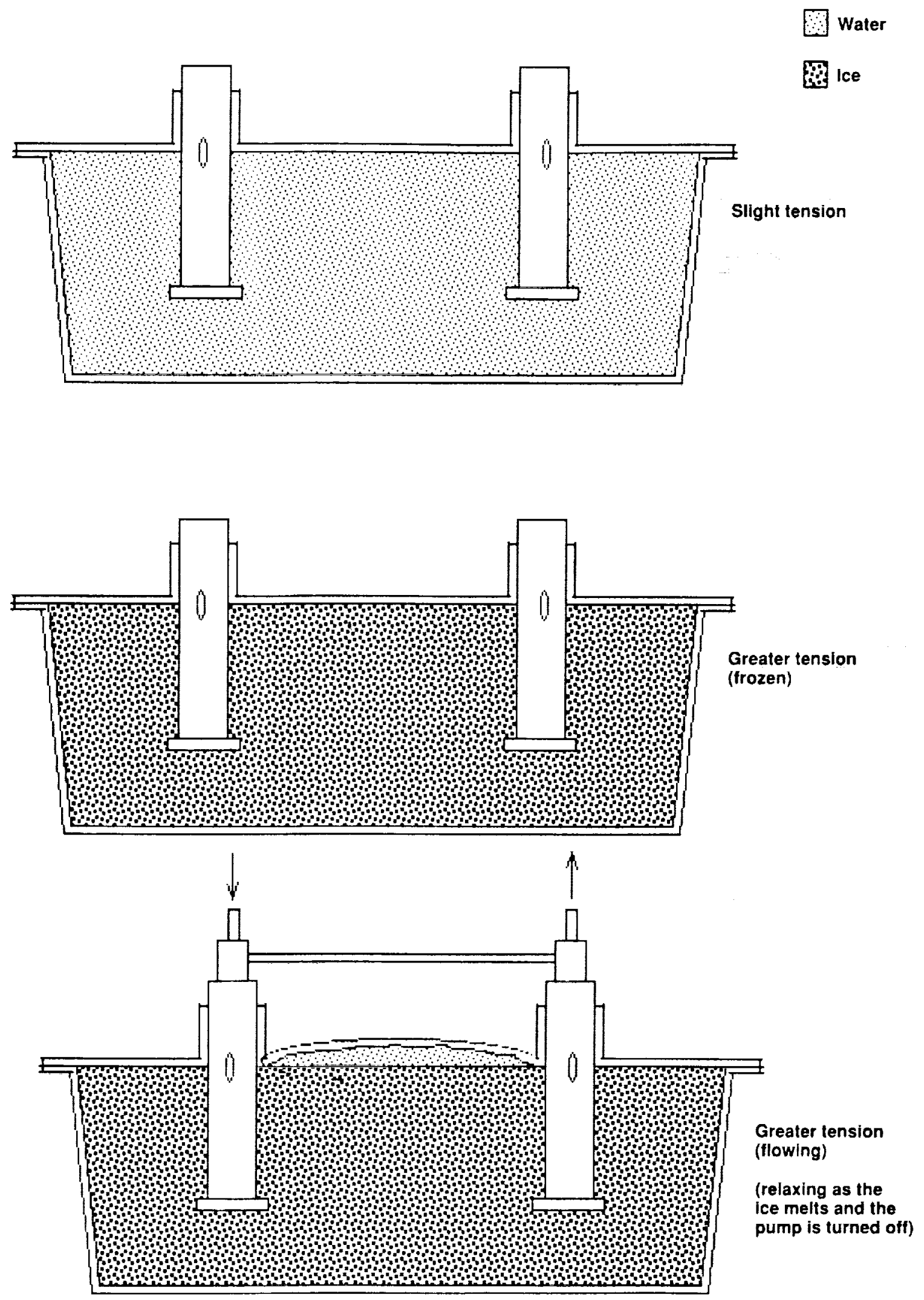

Figure 1. Diagram of regeneration and start-up of the direct-interface, fusible heat sink. 

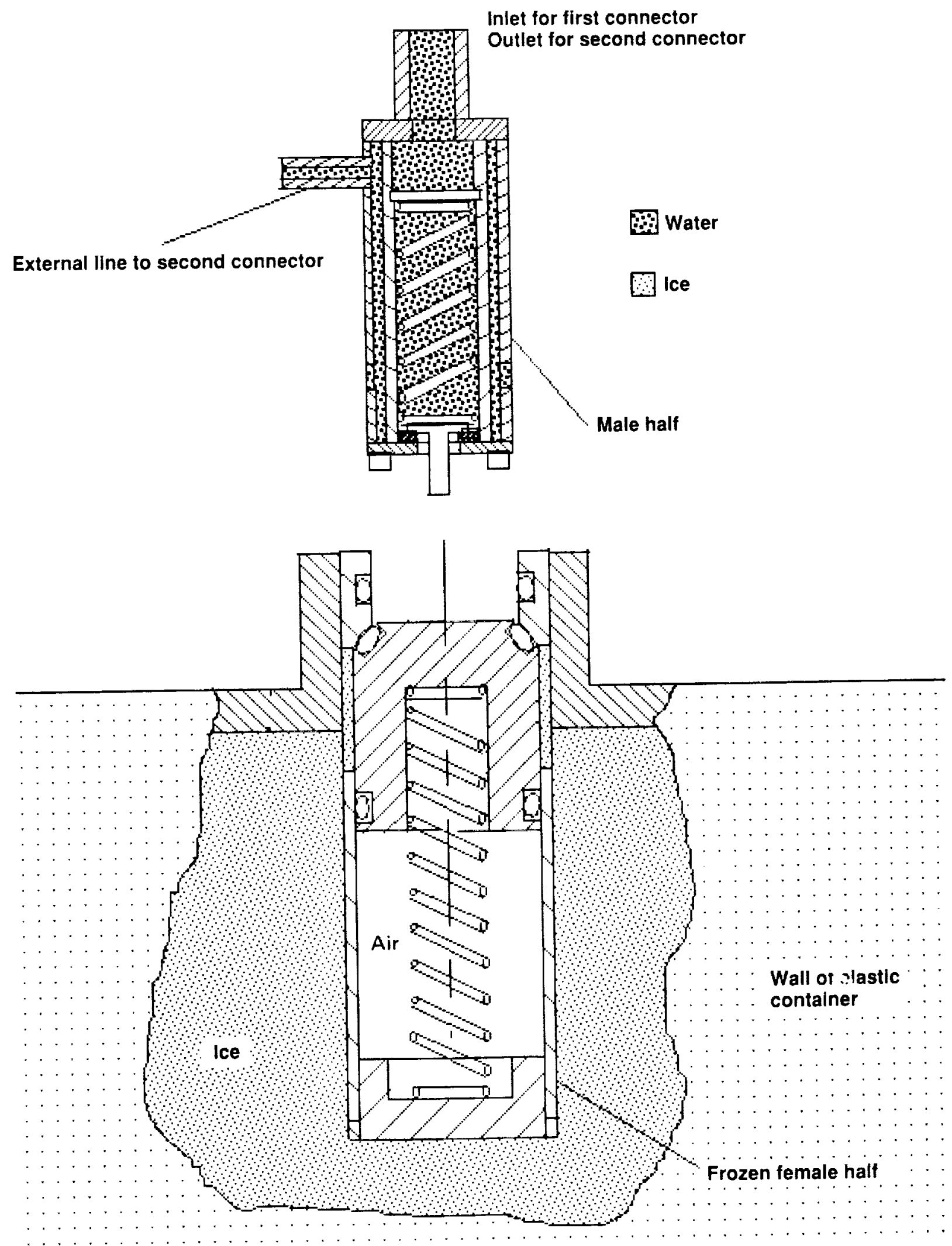

Figure 2. Unconnected frozen conditions for first or second connector, no flow possible. 


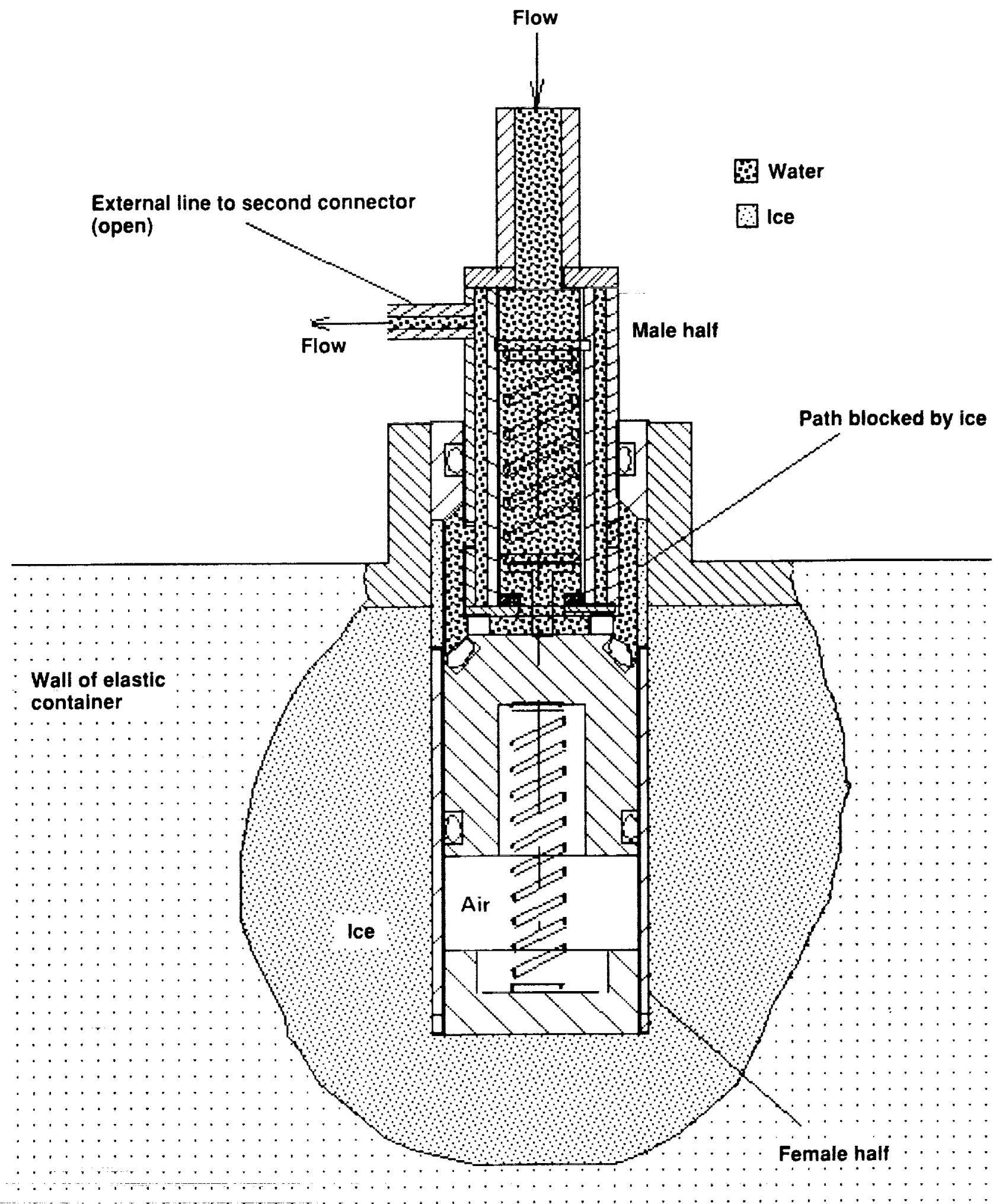

Figure 3. First connector (inlet), frozen condition, external flow possible (flow is reversed for second (outlet) connector). 


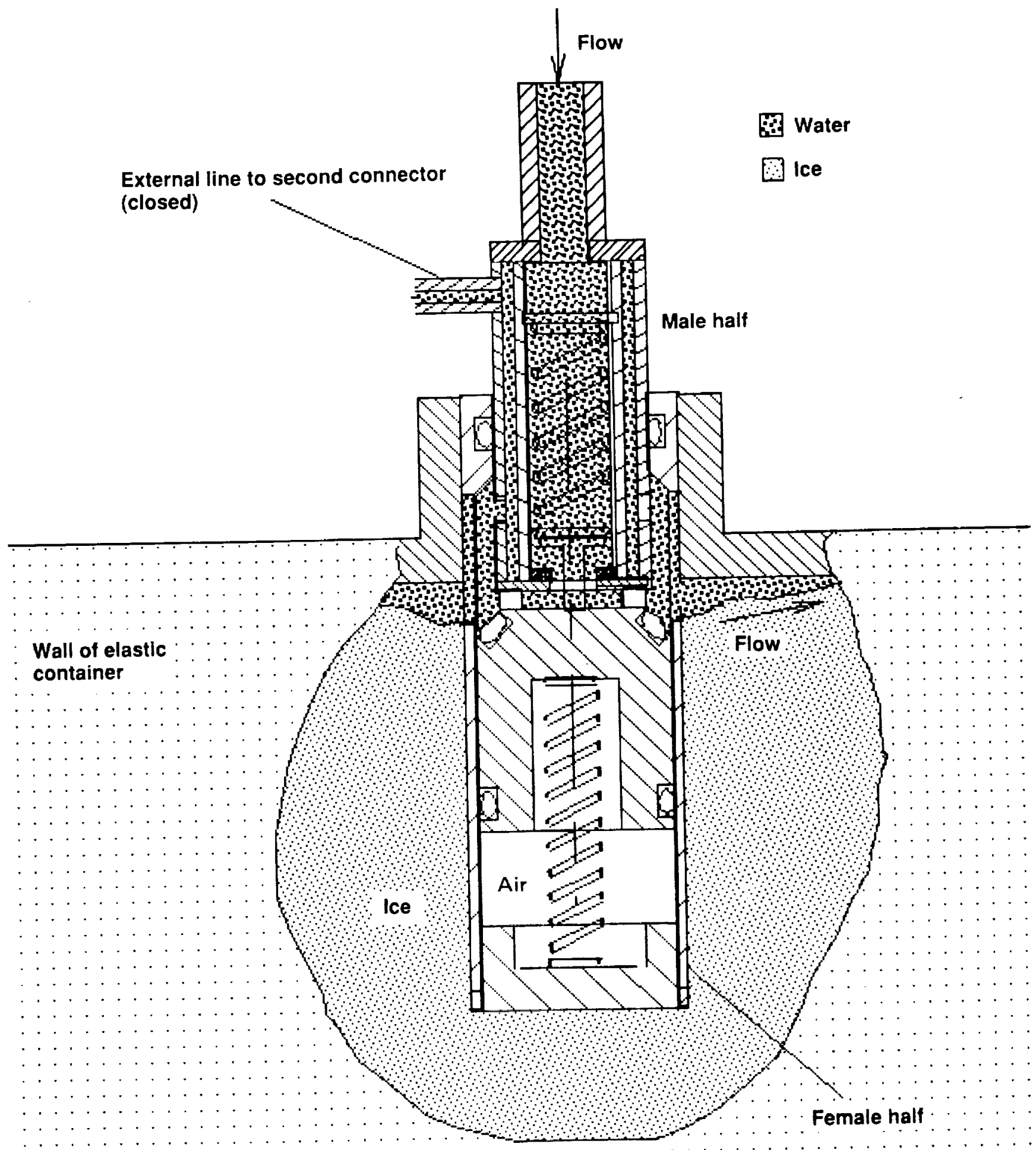

Figure 4. First connector (inlet), initial flow condition, internal flow is possible (flow is reversed for second (outlet) connector). 


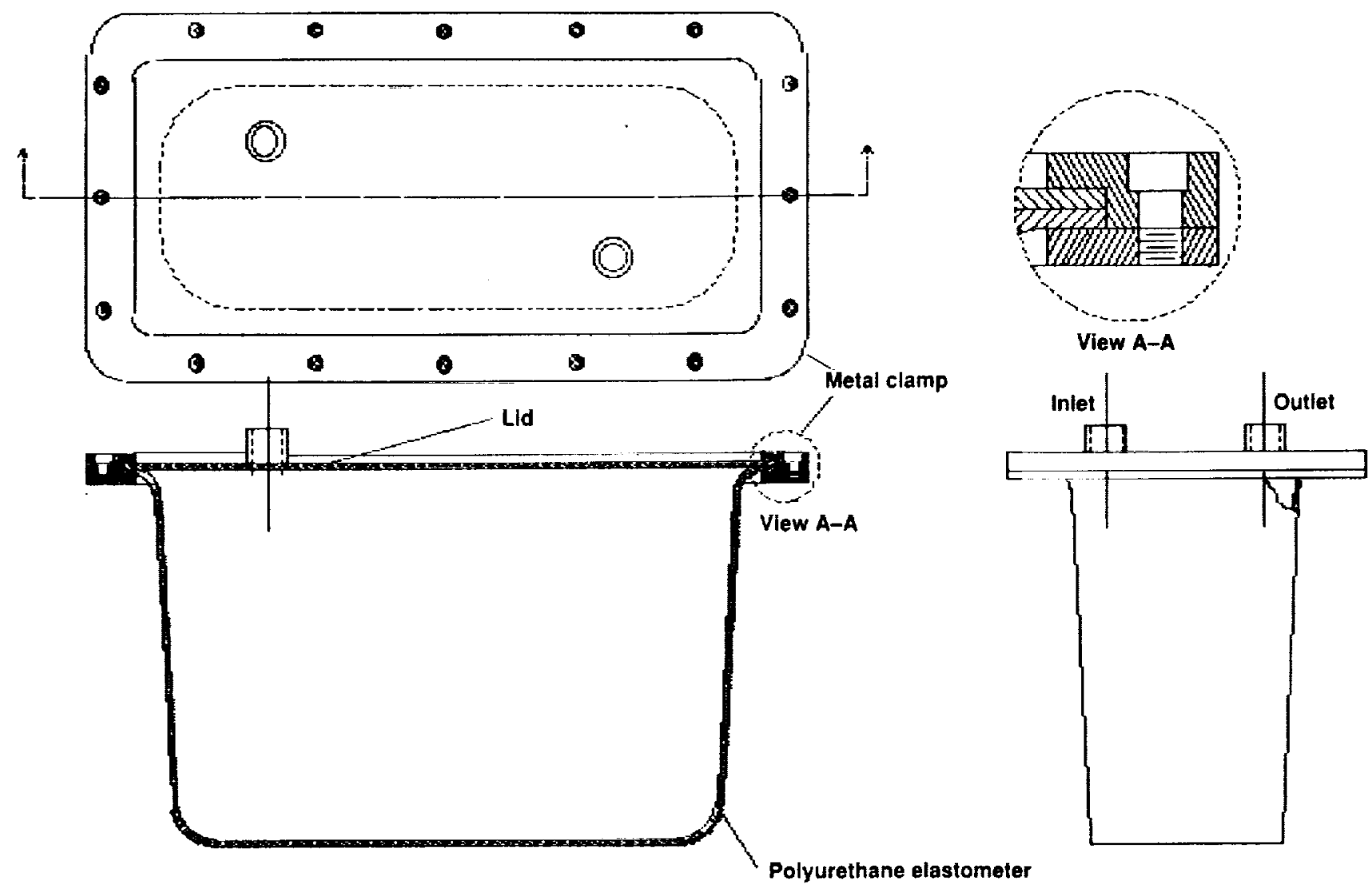

Figure 5. Details of direct-interface, fusible heat sink without connectors. 


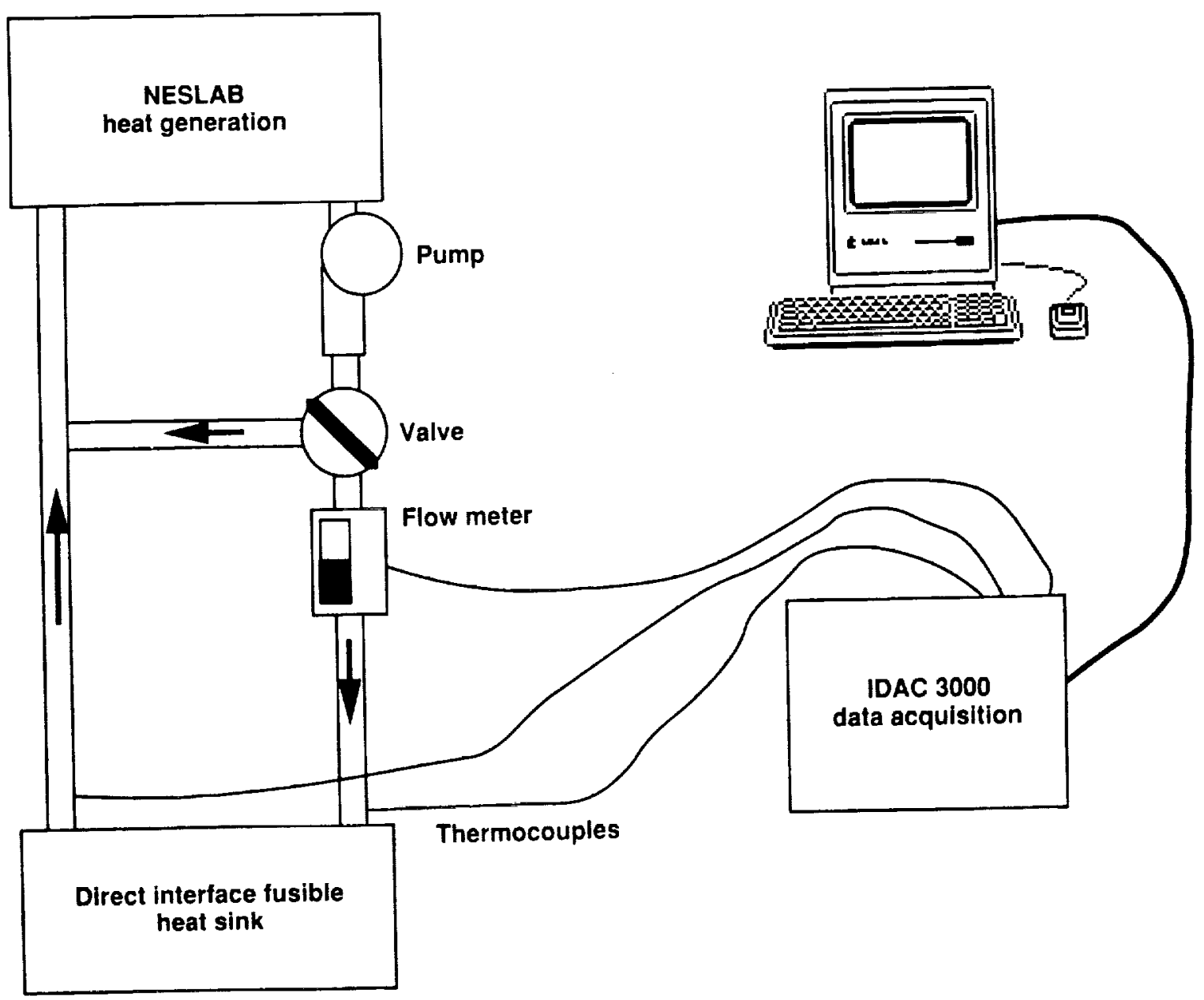

Figure 6. Schematic of test selup.

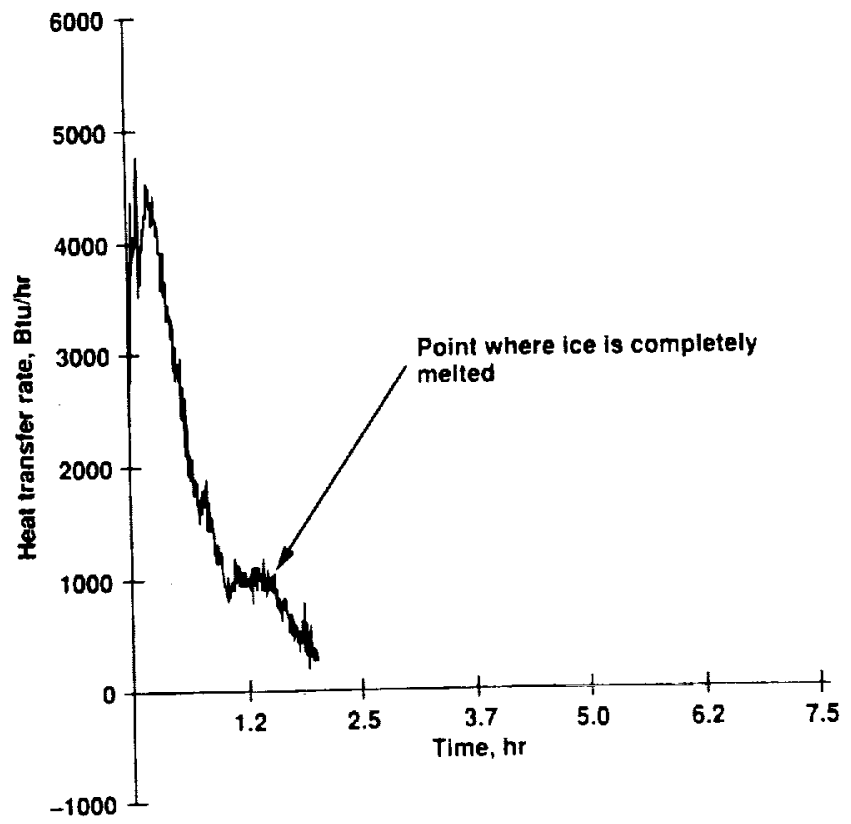

Figure 7. Heat-transfer time history of the first prototype configuration (no connectors/no baffles). 


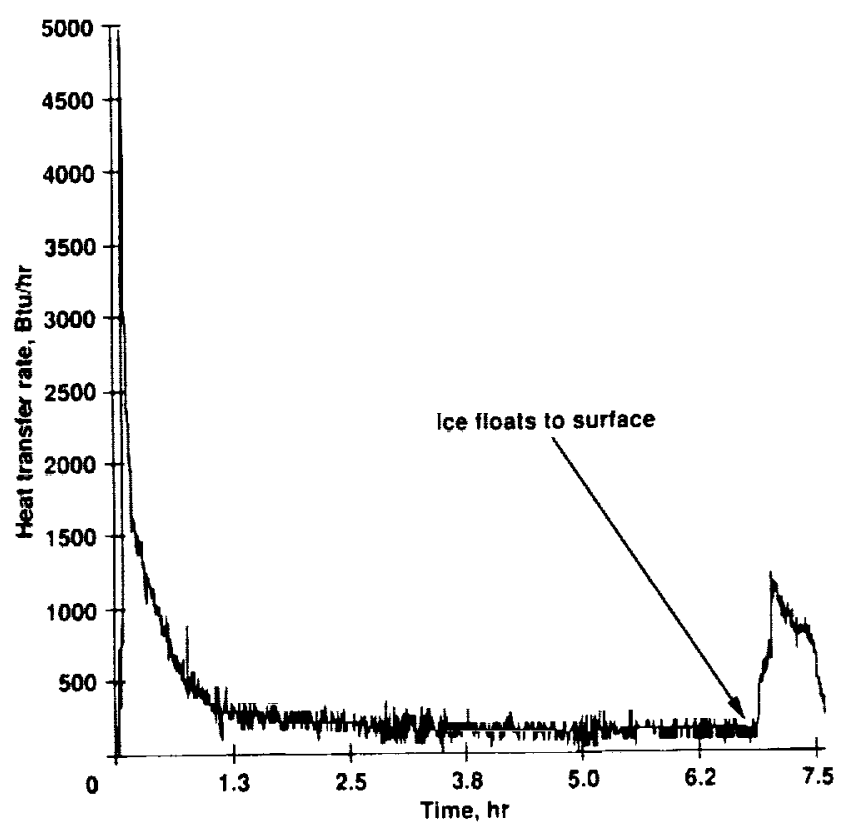

Figure 8. Heat-transfer time history of the second prototype configuration (connectors/no baffles).

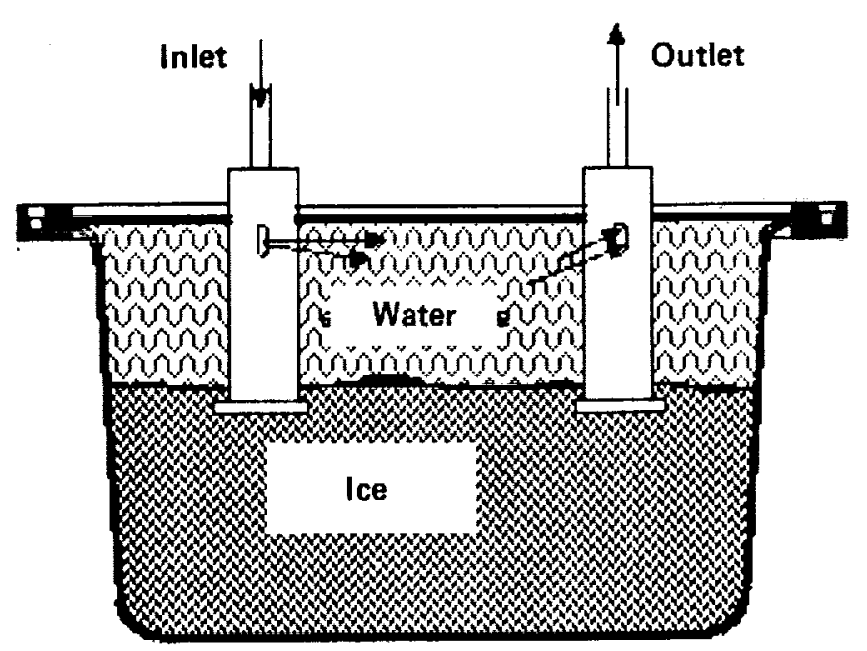

Figure 9. Channeling during melt.

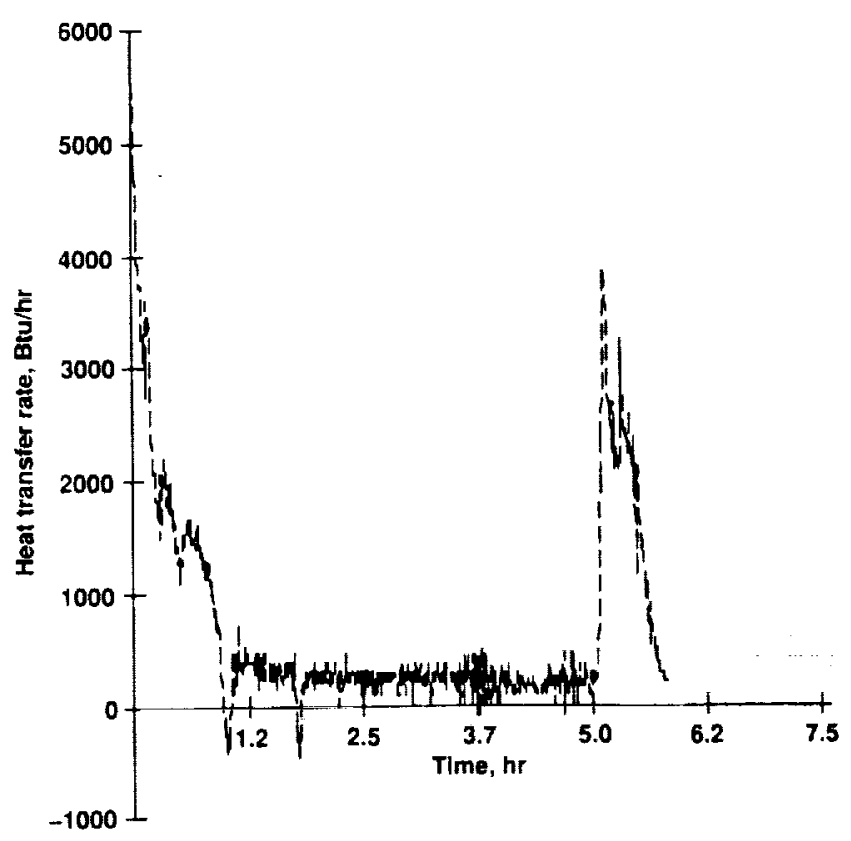

Figure 10. Heat-transfer time history of the third prototype configuration (connectors/baftles).

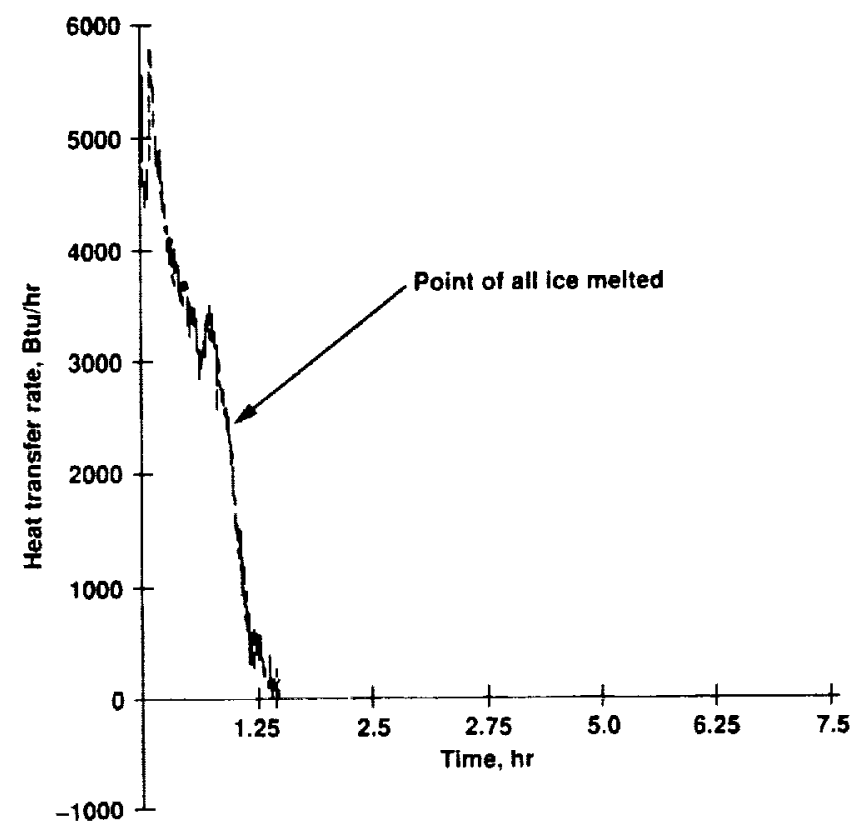

Figure 11. Heat-transfer time history of the fourth prototype configuration (connectors/no baffles/turbulent). 


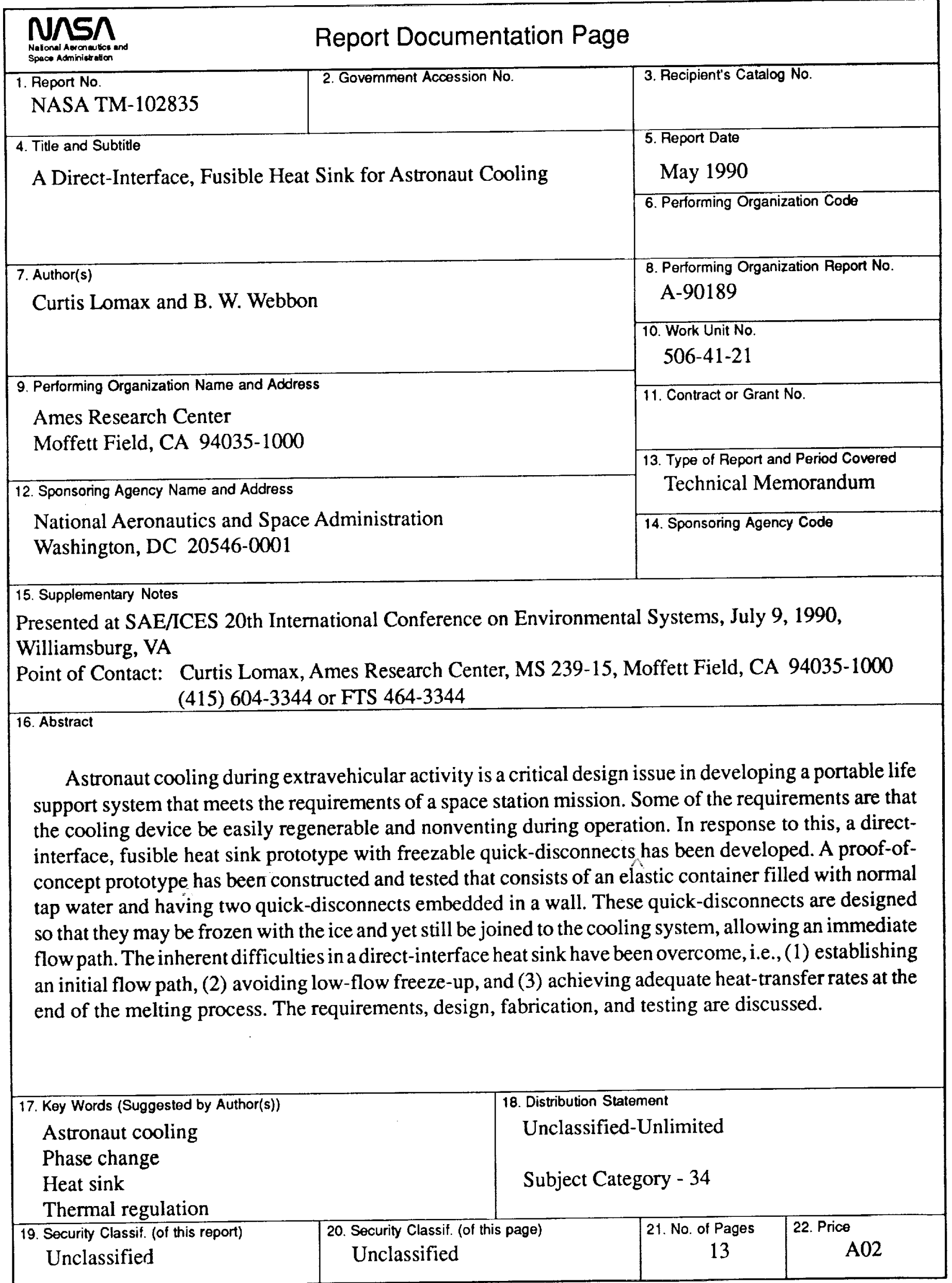


